\title{
Reframing HRI Education: A Dialogic Reformulation of HRI Education to Promote Diverse Thinking and Scientific Progress
}

\author{
Alberto Montebelli, Erik Billing, and Jessica Lindblom \\ University of Skövde \\ Giulia Messina Dahlberg \\ University of Borås
}

Over the last few years, technological developments in semi-autonomous machines have raised awareness about the strategic importance of human-robot interaction (HRI) and its technical and social implications. At the same time, HRI still lacks an established pedagogic tradition in the coordination of its intrinsically interdisciplinary nature. This scenario presents steep and urgent challenges for HRI education. Our contribution presents a normative interdisciplinary dialogic framework for HRI education, denoted InDia wheel, aimed toward seamless and coherent integration of the variety of disciplines that contribute to HRI. Our framework deemphasizes technical mastery, reducing it to a necessary yet not sufficient condition for HRI design, thus modifying the stereotypical narration of HRI-relevant disciplines and creating favorable conditions for a more diverse participation of students. Prospectively, we argue, the design of an educational 'space of interaction' that focuses on a variety of voices, without giving supremacy to one over the other, will be key to successful HRI education and practice.

Keywords: human-robot interaction, dialogic interdisciplinary HRI education

\section{Introduction}

Human-robot interaction (HRI) is a relatively recent and growing research field that is concerned with the ways humans might work, play, and otherwise interact with different types of robots. Contemporary robot technology is ready to deliver action that can be attuned to the specific needs of physically tight human-machine collaboration, under reasonable safety standards, with accurate and reliable performance. In other words, the time has come for 'personal/social robotics' that will mimic, and likely surpass, the diffusion of personal computers we have witnessed over the last two decades. Obviously, this technical achievement opens new perspectives and brings new challenges to the design of the interaction between humans and robots.

The steep challenge for HRI is not the creation of robots that can effectively collaborate with humans (i.e., it is not just a technical problem). Rather, it is the design of interaction modalities, such that humans will want to use the associated technological media in order to achieve and support their goals. This is the contemporary form of a historical problem - that is, the relationship of humans with their technological artifacts. In its relatively novel form, the problem is the design of ' a mutually shared interactive space' between human and machine. Social and emotional interaction may be the means (and the end) to the accomplishment of such a space (Dautenhahn, 2007a; Lindblom \& Alenljung, 2015).

Even a brief sketch of today's HRI should make explicit the dynamic nature of this emerging research field, whose body of work is still far from crystallized into a stable, structured, and mature form. As a discipline, HRI

Authors retain copyright and grant the Journal of Human-Robot Interaction right of first publication with the work simultaneously licensed under a Creative Commons Attribution License that allows others to share the work with an acknowledgement of the work's authorship and initial publication in this journal.

Journal of Human-Robot Interaction, Vol. 6, No. 2, 2017, Pages 3-26, DOI 10.5898/JHRI.6.2.Montebelli 
still needs a stronger tradition in the coordination and development of its interdisciplinary nature. The on ly HRIdedicated journal, 'Journal of Human-Robot Interaction,' started publication in 2012. The most influential dedicated HRI conferences are the ACM/IEEE International Conference on Human-Robot Interaction and the IEEE International Symposium on Robot and Human Interactive Communication (RO-MAN). The former had its first editions in 2006. While the first edition of the latter took place in 1992, its original name, 'IEEE International Symposium on Robot and Human Communication,' demonstrates how the concept of interaction had not fully developed yet. To date, there is no general convergence toward a set of key principles for HRI (e.g., Dautenhahn \& Saunders, 2011; Goodrich \& Schultz, 2007) (i.e., HRI is still pondering what HRI is and where it is heading).

The growing research field of HRI is thus facing several challenges. There is a need to build a foundation of theories, models, methods, and tools that characterizes HRI from different perspectives. All the above should also be formulated in pedagogical terms, serving the purpose of HRI education. Furthermore, there is also a pressing need for new evaluation techniques, because human interactions with robots significantly differ from interactions with more traditional computer-based systems (Dautenhahn, 2007a; Thrun, 2004; Young et al., 2011). According to Dautenhahn and Saunders (2011), there are several disciplines that contribute to HRI and bring different viewpoints and approaches to the field. They argue that it would be beneficial to consider and incorporate research from a wider outlook that may challenge and enhance existing frameworks and open new frontiers in HRI. More specifically, Dautenhahn (2007b) emphasizes that useful inspiration can be derived from the study of Human-Computer Interaction (HCI) and User Experience Design (UXD).

As the strategic commercial and social role of HRI becomes increasingly clear, several academic, social and commercial stakeholders have recently focused their attention on the need to rethink HRI education. A novel perspective and a new generation of HRI designers is needed. In the following sections, we will explore the reason for this and we will try to normatively address the special needs that educators of future HRI designers might encounter.

Our main contribution, schematically summarized in the InDia wheel presented in Section 3.4, is primarily aimed toward structuring our understanding and experience of HRI educational dynamics in a dialogic normative framework. An acceptable framework should seamlessly and coherently integrate into the teaching experience the variety of disciplines that contribute to the interdisciplinary nature of HRI. It should also encourage a diversified participation of interested students, develop their individuality and individual skills, and encourage them to think critically and independently.

We frame education in terms of a variety of activities that are normative in nature and that diachronically point toward a specific direction. Nevertheless, such activities also acknowledge the rele vance of the educational experience for what it is 'here and now,' rather than an endeavor solely projected toward a possible future. For students, education is a preparation for life, now as well as for tomorrow. This argument is also at the core of Dewey's philosophy of education: "The ideal of using the present simply to get for the future contradicts itself." (Dewey, 1938/1997 p. 49), thus implying an understanding of education in terms of lifelong learning.

Our work is organized as follows. Section 2 addresses the state of the art in HRI, as well as a foreseeable direction toward which the discipline is developing, the complex interaction of its concurrent research fields, and its internal tensions. This provides a necessary foundation for the correct interpretation of our position. In Section 3 , the core of our proposal, we sketch our take on the pedagogic aspects of HRI education, moving from an atomic to a cohesive perspective and formulating a pedagogic framework for HRI education. In Section 4, we analyze how contemporary educational methods could effectively and efficiently support HRI education. Finally, we summarize our work and draw our conclusions in Section 5, also remarking on the importance of diverse thinking, and therefore the necessity for a quickly growing discipline to incorporate contributions from a variety of scientific fields and social groups that, for several reasons, are traditionally underrepresented in science, technology, engineering, and mathematics education (STEM). 
Montebelli et al., Reframing HRI Education

\section{Identification of HRI}

\section{1 ' $R$ ' is for Robot}

Technological achievements in robotics are constantly redefining and expanding the constitutional nature of robots and the settings in which they can act. Accordingly, the concept of 'robot' is constantly changing (Alenljung, Lindblom, Andreasson, \& Ziemke, 2017; Dautenhahn, 2013). Hereafter, by robot, we mean an artifact whose configuration of sensors, actuators, and integrated control system provides a significant level of flexible, independent, and autonomous action. For example, following this characterization, a traditional computer is not a robot (i.e., it is functionally flexible but it does not provide action facilities) and neither is a traditional car (i.e., it provides action, yet it lacks satisfactory levels of flexibility and independence). A robotic vacuum cleaner scores low in flexibility but can offer some level of independent action (Powers, 2008). Robots can vary along multiple dimensions (e.g., the type of task the robot is intended to support, its morphology, interaction roles, human-robot physical proximity, and autonomy level; Yanco \& Drury, 2004). Although autonomous action is crucial for many types of robots, autonomy remains a problematic concept, receiving dramatically different interpretations in different communities (Lodwich, 2016; Vernon, 2014). For example, in industrial robotic automation, high autonomy implies that the human operator can specify the robot's behavior. In contrast, following the notion of autonomy present in biology, cognitive science, and to some extent also in HRI, an artificial agent is autonomous if its behavior cannot be fully controlled by an operator (Ziemke, 2007).

Robotic technologies can be grouped into three main categories based on their area of application: industrial robotics, professional service robotics, and personal service robotics (Thrun, 2004). Industrial robots operate in industrial settings under strictly controlled conditions, enclosed behind human-protecting cages, and deployed with a clearly stated and pragmatic function. Constraints are drastically relaxed for robots acting within naturalistic or social scenarios. Such robots are called to real-time decisions that cannot be easily predicted (and therefore preprogrammed) by humans. Professional service robots provide assistance in relatively unstructured environments (e.g., by collaborating with humans in shared workspaces (cobots), collecting nuclear waste, or performing wilderness search and rescue tasks or inspecting abandoned mines (Dautenhahn, 2013; Falter, Burks, \& Babcock, 1995; Goodrich \& Schultz, 2007; Thrun et al., 2003). Personal service robots, which have the highest expected growth rate in contemporary society, include robots designed to socially and emotionally interact with their users, thus addressing several crucial issues about quality and complexity of interaction. Such robots assist, support, or entertain people in public and domestic settings. Examples include robotic vacuum cleaners, receptionists, museum tour guides, and robots for edutainment, astronaut assistants, robot companions and assistants in elderly care and in rehabilitation therapy (Dautenhahn, 2013; Goodrich \& Schultz, 2007; Thrun, 2004).

Robots may belong to several different morphological types. For example, human- or animal-like robots, constituted of rigid or soft parts, coexist with more traditional mechanical-appearing robots. The embodied type of the robot has several implications in HRI (Lindblom \& Alenljung, 2015; Thrun, 2004). Embodied interaction means bringing interaction into the human's real physical world to involve the human's own physical being in the world, moving the interaction off the screen and into the real lived world (Hartson \& Pyla, 2012). The activities of the robots and humans take place in physical space and need to be coordinated 'here and now' (Dautenhahn \& Saunders, 2011). Different embodiments introduce differences in terms of interface capabilities, potential user groups, skills, and the different contexts of use, in comparison to more traditional interactive systems (Thrun, 2004).

\section{2 ' $\mathrm{H}$ ' is for Human}

The development of robots is expected to have an increasing importance in everyday life for a growing number of people. While robots are currently starting to populate human environments, their scope and their level of participation in everyday activities are becoming more sophisticated (Alenljung et al., 2017). From a human perspective, the purpose of robotic technology is to make it possible for a person to accomplish something that could not be done otherwise, to facilitate a certain task, or provide entertainment (Goodrich \& Schultz, 2007). Designing robots requires considering who is going to use them and in what context. Different types of robot interfaces and interaction styles may be appropriate depending on the specific nature of the supported activities. 
Montebelli et al., Reframing HRI Education

By considering the way humans act and react when interacting with robots, robots can be designed to support their needs as well as provide powerful functionality. This can be achieved by investigating and analyzing cognitive, social, and organizational aspects of human behavior when using technology. The human repertoire of interactive strategies with technology is founded on a long co-evolutionary history. Therefore, humans typically have high expectations and demands on the interactive capacity of technological products and digital artifacts. Relevant aspects include a wide range of social features, such as expressing and perceiving emotions, communicating verbally and non-verbally, displaying personality, recognizing interaction partners, and learning socially (Fong, Nourbakhsh, \& Dautenhahn, 2003). From the human point of view, independent of the user's skill level, an acceptable product is easy to use and seamlessly fits into its intended context. These basic requirements sustain a corollary of more complex demands, globally characterizing UXD as the capacity to positively impact on people's feelings, as caused and shaped by the use of technology in a particular context (Hartson \& Pyla, 2012; Hassenzahl, 2013).

Good usability and positive UXD underpin the proliferation of robots in society. A negative user experience elicited by a specific robot entails reluctance to its use, erroneous handling, and might determine a proliferation of a generalized bad attitude toward robots. Therefore, relevant design, development, and evaluation principles of UXD are essential for the systematic design of a positive and rewarding robot UXD (de Graaf \& Allouch, 2013; Hartson \& Pyla, 2012; Hassenzahl, 2013), beginning with the first use of the robot (Hartson \& Pyla, 2012; Hassenzahl \& Tractinsky, 2006), in order to fully achieve the intended benefits for its users in a certain context (Alenljung et al., 2017). Different aspects of the interaction require evaluation, including acceptance, usability, learnability, safety, trust, and credibility. While some of these aspects are typically covered in depth, some tend to be overlooked by HRI research (for further details, see Alenljung et al., 2017; Lindblom \& Andreasson, 2016).

Although technical mastery is a necessary condition for sound HRI design (e.g., for the customization of robotics platforms), it is doubtful that this alone is sufficient (Miller \& Nourbakhsh, 2016). The recent and rapid development of autonomous technology emphasizes the importance of considering various aspects of human-robot interaction from a human-centered perspective. Taking on the human-centered view and stressing the importance of creating a positive UXD in the study of human interaction with robots is of major concern in order for technology to provide a long-term added value to people's lives (Dautenhahn, 2007a). Higher education in interaction design, HCI, and UXD could extend its focus to the design of interaction between humans and robots, instead of solely focusing on more traditional user interfaces such as the web, smartphones, and other man-machine interfaces.

\section{3 ' $\mathrm{I}$ ' is for Interaction}

The aim of HRI has been characterized as "the design, understanding and evaluation of robotic systems, which involve humans and robots interacting through communication" (Goodrich \& Schultz, 2007). The modality of interaction between user and robot can vary significantly, depending on user-, task-, and context-based conditions (Alenljung et al., 2017). It can be of physical or non-physical nature. It can be either remote (i.e., the human and the robot are spatially or even temporally separated), or proximate (i.e., the human and the robot are co-located) (Goodrich \& Schultz, 2007). The interaction can be indirect, when the user operates the robot by commanding it, or direct, when the communication between the user and robot is bidirectional and the robot can act on its own (Thrun, 2004). The role of humans in relation to robots can vary: The human can be a supervisor, operator, mechanic, teammate, bystander, mentor, or information consumer (e.g., Alenljung, et al., 2017; Goodrich \& Schultz, 2007; Scholtz, 2003) and can directly transfer physical human skills to robots (Montebelli, Steinmetz, \& Kyrki, 2015; Steinmetz, Montebelli, \& Kyrki, 2015; Thabet, Montebelli, \& Kyrki, 2016; Tykall, Montebelli, \& Kyrki, 2016).

The same recent technical development that has determined the passage from traditional industrial robots to robots operating in the physical and social space of humans poses higher demands on the quality of interaction between human and robot. Initially, research has focused on aspects of safe interaction between robot and its material environment, including humans. Once robots start sharing a common environment with humans, they also need to operate in observance of social and emotional aspects of the interaction (Lindblom \& Andreasson, 2016).

Socially interactive robots are defined as "robots for which social interaction plays a key role" (Fong et al., 2003, p. 145). They should display social intelligence (i.e., qualities that reflect human social expressions, such as 
emotional appearance, emotion perception, and advanced communication through dialogue, gaze, and gesture) (Fong et al., 2003). According to Dautenhahn (2007a), social HRI research can be categorized into three different approaches: robot-centered HRI, robot cognition-centered HRI, and human-centered HRI (Fig. 1). Robot-centered HRI views the robot as an autonomous entity and the human counterpart as the robot's 'caretaker' who should identify and attend to the requests of the robot. In robot-cognition-centered HRI, the fundamental problem is to provide robots, considered as intelligent systems, with a satisfactory level of cognitive capacity. In human-centered HRI, the human perspective is emphasized in striving toward robots that appear comfortable and intuitive in human interaction. From this perspective, HRI design should address issues of acceptability, usability, and believability. Furthermore, it should consider human expectations and perceptions of robots, and human attitudes toward them.

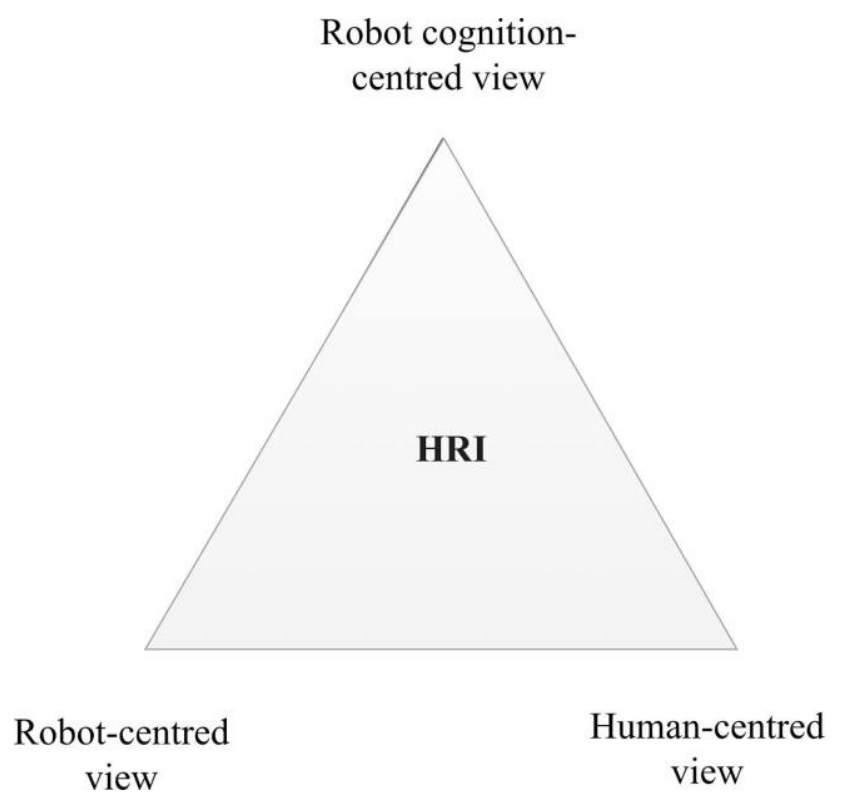

Figure 1: The conceptual space of approaches for social interaction in HRI research (modified from Dautenhahn, 2007a, p. 685, by Andreasson \& Lindblom, 2016).

In order to allow robots to "inhabit our living environments," all three approaches need to be synthesized to enhance social interaction (Dautenhahn, 2007a). However, human-centered HRI has so far received limited attention compared to the other two approaches, because most robots have not yet reached the functional level of advanced technical capacities that are necessary for addressing the human-centered perspective. Recently, different aspects related to the social and emotional quality of the interaction have been addressed in the HRI literature, including engagement, safety, intentions, acceptance, cooperation, emotional response, UXD, likeability, and animacy (Lindblom \& Andreasson, 2016).

Careful analysis of what constitutes natural user interfaces (NUI) is required. Although NUI often implies interacting with technology through gestures and similar means, Norman (2010) argues that gestures are not intuitive, per se. They are not innate but acquired through social interactions and, since cultural differences in gesturing do exist, using gestures to communicate with robots offers a solution that does not fit all humans. In a 
Montebelli et al., Reframing HRI Education

similar vein, Dautenhahn (2013) criticizes the widespread assumption within the HRI field that a correct interaction with robots should mimic natural (human-human) social interaction and communication, raising several issues related to qualifying "natural" human behavior.

The recent proliferation of research and applications of human-robot collaboration (HRC) in complex working environments (e.g., in industry, offices, homes, and hospitals) is the result of the aforementioned technological development in robotics. In HRC, humans and robots collaborate with the aim to reach a common goal. Human(s) and robot(s) should function like a team, fulfilling a joint task with their diverse competence complementing each other's skills (Vernon, 2014, chapter 9). This requires robots capable of interpreting human intentions (i.e., recognizing actions, interpreting sequences of actions, and recognizing emotional facial expressions; Lindblom \& Alenljung, 2015). In current implementations, the human peer typically states the goal, while the robot's task is to assist the human in pursuing the common goal (Bauer, Wollherr, \& Buss, 2008; Charalambous, Fletcher \& Webb, 2015).

\subsection{HRI as an Intrinsically Interdisciplinary Field}

As emphasized in previous sections, HRI is an intrinsically interdisciplinary research field, encompassing disciplines that are traditionally perceived as distant in the academic taxonomy. For example, technical subjects such as artificial intelligence, automation, computer science, cybernetics, engineering, mechanics, robotics, and statistics are all highly relevant for the study of HRI. Many behavioral and physiological subjects are just as important, including, but not limited to, anthropology, cognitive science, human factors, linguistics, psychology, physiology, philosophy, and social sciences. In addition, there are the neighboring disciplines of interaction design, HCI and human-machine interaction. Such a heterogeneous set of competences overarches a wide spectrum of methods and approaches (e.g., quantitative and qualitative methodologies, positivistic, hermeneutic and post-structuralistic approaches). While cultural cross-fertilization and holistic integration of such a diversified expertise represents a desirable goal, conflict rather than mutual understanding often emerges. The mindset and conceptual toolbox of different specialists converging around a common HRI project might be surprisingly different, leaving space to the risk of misinterpretations of underlying philosophical, methodological and theoretical foundations that may not be explicitly articulated among the different fields, and erroneously considered as common knowledge across different communities. This might result in incorrect assumptions, misconceptions of obtained results and misleading conclusions. "Autonomy," "embodiment," "user involvement," and "imitation" are a few examples of interdisciplinary concepts used in several HRI-relevant areas, while their specific interpretation presents significant inter-disciplinary variations.

Dautenhahn (2013) observes how researchers may approach the field of HRI with considerably different motivations. Some aim for robotic systems for real-world applications (e.g., service robots for personal assistance), developed from a human-centered or from a different perspective on HRI. Psychologists, anthropologist, or ethologists use robots as tools in order to understand fundamental issues of how humans interact socially and communicate with others and with interactive systems. Cognitive science and AI researchers implement intelligent systems, using robots as embodied instantiations, testbeds, or proof of concepts of such cognitive systems. Finally, some are interested in studying the interaction of humans and robots, per se (i.e., exploring how different humans perceive different types of robots, robot behaviors, and social cues).

HRI is closely related to HCI. Both disciplines address the problem of human engagement with interactive systems (e.g., with computer systems, smartphones, or robots). Initially considered as an interdisciplinary subject, contemporary HCI is a research discipline in its own right, with an established community, conferences and scientific journals, and specific paradigms, approaches, and methods. HCI study programs exist at undergraduate, master, and PhD levels, with dedicated syllabi and textbooks. Professorships in HCI are routinely appointed, although HCI scholars are often embedded within computer science (or similar) departments. Altogether, these are concrete indicators of a disciplinary field, although they do not yet indicate an institutionalized discipline. However, understanding the historical evolution of HCI requires familiarity with the challenges that the discipline has faced and still partly faces (e.g., Bødker, 2006, 2015; Harrison, Tatar, \& Sengers, 2007; Rogers, 2012; Shackel, 2009). If HRI will follow a similar evolution into a cohesive discipline or will rather develop as a collection of research questions that have to be addressed by several independent disciplines remains an open question (Weiss, 2012). 
Montebelli et al., Reframing HRI Education

With respect to HCI, HRI poses additional challenges: i) Robots are (partly) autonomous agents that act independently from the human user; ii) Robots are embodied, therefore they crucially occupy the physical space and tend to promote a real-time modality of interaction to a larger extent than traditional interactive systems; iii) The physical realization of robots offers unique design challenges and opportunities (e.g., the implementation of drastically different robot morphologies that may affect human users differently and more deeply than more traditional text-based, command-based, or graphical user interfaces (GUIs)); iv) contemporary robotic platforms often require custom designs (i.e., hardware and software solutions are often incompatible with other platforms (or even previous versions of the same platform); and v) differently from other interactive systems, humans tend to ascribe agency and intentionality to robots, and this can be beneficial to the interaction (Ziemke, Thill, \& Vernon, 2015). Therefore, we argue that these differences are sufficient to consider HRI a field of its own, rather than a subset of HCI as elsewhere suggested (e.g., Yanco \& Drury, 2004). Nevertheless, several HCI methods and techniques for design and evaluation of different aspects of human-technology interaction can be ported and modified to better fit the specific needs of HRI (Dautenhahn, 2007b).

Research in HRI is often carried out via 'user studies,' strongly focusing on human reactions and attitudes toward robots. Research in this area is heavily influenced by experimental psychology and previous HCI research. It should be noted, however, that there is a significant difference between what Dautenhahn (2013) characterized as 'user studies' and the approach of 'usability studies' within HCI. The latter focuses on quantitative and qualitative evaluation of the user's experience during interaction with interactive systems, usually according to some ISO standards. Dautenhahn (2013) advocates HRI as a synthetic research domain and phrases the key challenge and characterization of HRI as follows, "HRI is the science of studying people's behavior and attitudes toward robots in relationship to the physical, technological, and interactive features of the robots, with the goal of developing robots that facilitate the emergence of human-robot interactions that are efficient (according to the original requirements of their envisaged area of use), acceptable to people, and meet the social and emotional needs of their individual users as well as respecting human values."

\subsection{Creative Tension in HRI}

As a starting point for reflection on the interdisciplinary challenge in HRI, Weiss $(2012,2016)$ analyzed a collection of informal and stereotypical statements frequently heard in the HRI community, and then she reported three classes of creative tension in HRI. Each class is interpreted in the light of the epistemic living spaces, a concept aligned with Jasanoff's (2004) co-productionist approach, which emphasizes how science is interwoven with society.

The first class, coping with different knowledge, implies the existence of a variety of backgrounds and knowledge that needs to be integrated into a single research topic. For example, a stereotypical statement in this class formulated by a human-centered researcher would be: "I am now taking this AI class, in order to know what roboticists are doing." A robot- or robot cognition-centered researcher might claim: "I am reading this social science book to know how to compile a questionnaire for my user study." These examples highlight how in interdisciplinary research not all the needed concepts and tools are available within one's own subject. HRI researchers necessitate mastery of a broad knowledge space, ranging from robotics to user and/or usability studies. Coping with different knowledge constitutes an orientation phase (Weiss, 2012, 2016), which often is a point of tension identified early on in the career of an HRI researcher. Weiss advocates the need for 'guiding maps,' enabling HRI researchers to identify central epistemic and subject issues that are relevant in their specific context, and supporting and structuring the emergence of a personal understanding of what is expected and needed to promote a career in HRI.

The second class, demonstrating skills, suggests a competitive drive among researchers from related HRI disciplines. A human-centered researcher might claim: "I will demonstrate to them that a social scientist also knows how to program" or "a study without actual users is not valuable for HRI." A robot-/robot cognition-centered researcher might claim: "I will demonstrate to them that psychologists are not needed to conduct experiments" or " $a$ study without a real, autonomous robot is not valuable for HRI." Such self-assertive stances appear immature because they omit the interdisciplinary attitude and skills necessary to accomplish interdisciplinary work. It can be 
Montebelli et al., Reframing HRI Education

considered a positioning phase (Weiss, 2012; 2016), characterizing early attempts to find a personal space and role in HRI research. This tension often materializes before the creation of an adequate individual epistemic living space, identity, and unique personal contribution in the HRI community. Weiss $(2012,2016)$ suggests that these kinds of stances might induce researchers to the formulation of strong and premature claims about the prevalent methods in the solution of specific research problems.

The third class, institutional aspects, indicates the creation of 'scientific unions.' A human-centered researcher might say: "If we want to get project money we need to focus on social acceptability and ethics." Robot-/robot cognition-centered claims might be: "If we want to get project money we need to focus on cognitive systems and brain interfaces." This tension, typically emerging in later phases of a HRI research career, determines a stabilizing and expanding phase, during which senior researchers try to create a safe foundation for their activities, from which more challenging territories may be explored (Weiss, 2012; 2016). Weiss points to the risk that researchers in this condition might redirect their career path to more traditional fields/disciplines, rather than pursuing interdisciplinary HRI research. The choice to quit interdisciplinary research might be more rewarding in terms of publication in highly ranked journals and conferences, of academic merit recognitions, and job offers that fit their qualifications. However, the conditions for HRI researchers are currently improving under this aspect: reputable journals and conferences are emerging, and new positions are specifically being offered to HRI researchers.

Weiss's analysis also pointed to the unsatisfactory deployment of the attachment phase (Weiss, 2012; 2016). This additional crucial phase ideally follows the orientation phase and fosters students with "normative imagination of [...] knowledge production," providing the next generations of HRI practitioners and researchers with HRI specific interdisciplinary methods and tools. Therefore, Weiss's reflection on the "creative tensions" of the "epistemic living spaces" in HRI research fully discloses the question, formulated in the previous subsection, about the future of HRI. According to Weiss $(2012,2016)$, two strands of HRI education are viable. On the one hand, HRI students could be educated to achieve the theoretical knowledge and methodological competence needed as future interdisciplinary HRI researchers, promoting and developing their affection for interdisciplinary work, emphasizing cooperation among different disciplines. On the other hand, HRI education could pursue the creation of a unified HRI discipline, calling for the integration of specific HRI methods and competences, emphasizing integrated collaboration among different disciplines, which is the approach that we advocate in this article.

\subsection{Toward the Future of HRI}

Richert et al. (2016) emphasize the need to prepare engineers for the so-called fourth industrial revolution. In Industry 4.0, specialists in engineering and computer science collaborate, within a global environment, with experts in several other disciplines to develop and deploy advanced information and communications technology (ICT) systems. Richert et al. (2016) identify several requirements and challenges for higher education in this area. First, the problem solving process of complex, interdisciplinary, and open-ended issues in industry demands creative, analytic, and innovative abilities to handle and use big data, and consequently, comprehensive knowledge and skills in computer science and informatics. Second, new workspaces, characterized by virtual communication, collaboration, and remote control, are emerging. Third, human workers are becoming part of hybrid-human-robotteams that should collaborate via intuitive user interfaces, resulting in new work tasks and competences. Fourth, the needed competences include soft skills, such as the ability for collaborative working in interdisciplinary teams, knowledge of different cultures, and metacognitive skills. In the new scenario, specific expertise needs to be backed by the capacity of global thinking, interdisciplinary knowledge, and a holistic understanding of the organization that might be acting on a global market where manufacturing sites are distributed worldwide (Richert et al., 2016). Industry 4.0 poses high demands on current standardized engineering education, questioning content and methods of engineering education, and setting high educational standards for the formation of a suitable mindset in future leaders and labor (Schuster, Groß, Vossen, Richert, \& Jeschke, 2015). Additionally, the borders between higher education and companies tend to become blurred due to the need for lifelong learning that keeps workers up-to-date with the rapid development in industry. Such challenges, tensions, and contradictions are at the core of what we frame in terms of dialogic pedagogy and dialogic activities in HRI education, further elaborated in Section 3. 
Human-robot-collaboration (HRC) is regarded as a major aspect of the future Industry 4.0 (Richert et al., 2016). HRC entails humans that cooperatively work with robots in dynamic, changing, and unpredictable settings where both "partners" should assist and learn from each other and automatically respond to changes. This requires research and development (R\&D) to determine how these hybrid collaborative systems should function and distribute work. HRC educational requirements include novel programs in HRI and HRC, and empirical studies to investigate and analyze how students may learn the necessary skills for efficient and safe work in shared workspaces. The design and development of Virtual Learning Environments (VLE) appears crucial in this context. VLEs will allow realistic simulations of several future human-robot shared work scenarios, thus implementing testbeds for HRC-related $\mathrm{R} \& \mathrm{D}$, informing the design, and fostering interaction and team building between humans and robots. In education, VLEs will offer novel opportunities for coaching and learning, upon validation of the transferability of learning between simulated and real or virtual workspace (Richert et al., 2016).

In a short- to mid-term time frame, HRI will be integrated into the human society, acting in a supportive role. Robots will likely be ubiquitous, engaged in all kinds of activities side by side with humans, often substituting them. With its campaign Horizon 2020, the EU Commission is deploying significant investments for research in assistive robotics, backing independent living for the physically challenged and the elderly. Robots will support humans in their households, assist our daily routines, monitor and report the degeneration of human behaviors, prevent accidents, and provide rehabilitation when necessary. In parallel, the road toward more daring scenarios is being paved with the incorporation of technology into the human body, with the creation of bio-technological human symbionts (Clark, 2003). For example, this is materializing in the form of Brain-Machine Interfaces (e.g., Hochberg et al., 2012) and sensorized prosthetics (e.g., Raspopovic et al., 2014). On a slightly longer term, these biotechnological interfaces may become even more relevant in interaction with robots and possibly even constitute their own subfields of HRI.

\section{From an Atomic to a Comprehensive Perspective on HRI Education}

In the previous section, we offered a general overview of the multifaceted aspects of HRI that motivate our pedagogical proposal. We have highlighted those elements and concepts in HRI that are central in the present and prospective articulation of HRI education and introduced several theoretical ideas on which our proposal builds. In this core section, we start focusing on pedagogic aspects of HRI education.

HRI education is challenging from several points of view. First, HRI lacks an established tradition in the field, both in terms of general achievements and pedagogical conventions. For example, much interdisciplinary work is still required to better understand how to generate social interaction (Murphy, Nomura, Billard, \& Burke, 2010) and on how to evaluate HRI (e.g., Alenljung et al., 2017; Dautenhahn, 2007a, 2007b; Lindblom \& Andreasson, 2016). The lack of a generally accepted syllabus for an HRI course is clearly mirrored by the absence of an introductory HRI textbook (Berry, 2015; Murphy et al., 2010; Weiss, 2012). Due the relative novelty and the complex nature of the subject, literature on HRI education is still quite scarce. Contemporary programs related to HRI education tend to emphasize the most technical aspects of HRI, addressing the problem from a limited, sub-discipline-bound viewpoint. Such a specialist-driven, technical perspective does not address the interdisciplinary and holistic educational vision that inspires our position. Second, HRI should integratively articulate a large variety of interdisciplinary competences, to an extent that is probably unmatched in current academic education. Third, HRI should be generally open to students with heterogeneous educational portfolios and interests. Fourth, HRI relies on costly and technically demanding robotic platforms, including hands-on training, which appears crucial for a sound, challenging yet engaging student experience.

In the following, we provide a discussion about educational theory and practice, in order to introduce our suggestions for the creation of HRI education that sheds light on the challenges and the potential of diversity. Before we begin to analyze the role of education in terms of theories and practices for HRI as a unified educational field, we briefly consider our positions on learning as a socially oriented activity. Our socially oriented position recognizes interaction and the deployment of tools (including digital technologies) as a central and fundamental dimension in 
Montebelli et al., Reframing HRI Education

the processes of socialization and identification of individuals. This entails an understanding of learning as a dimension of human life that cannot exist in a social vacuum or in some neutral fashion (Bagga-Gupta, Messina Dahlberg \& Winther, 2016). Rather, a central tenet behind this view is a conceptualization of the human mind as hybrid "half analogizers, with direct experience of the world, and half symbolizers, embedded in a cultural world" (Donald, 2001, p. 157). Culture is, thus, a link between the two modes, the sensory-cognitive system of the brain and the symbolic one (Donald, 2001). This linking is instantiated through the use of symbolic systems and language, being the tool of tools (Vygotsky, 1978), in a process called mediated action.

A sociocultural perspective on learning emphasizes communicative practices and the use of tools as the conditions that shape the ways in which human beings understand and relate to the world out there. Such a view allows us to frame educational activities as follows: i) socially oriented, ii) not bound to individual's biological conditions, and iii) distributed across networks of activities across time and space (see Hutchins, 1995; Resnick, 1994; Rogoff, 1990). Here, we argue, language and thought are in symbiotic relation to one another. From that follows that learning (in terms of creation of knowledge and a broader repertoire of experience) is only visible in the interaction among people and their cultural tools. Hence, a focus on the communicative aspect of the education experience is needed in order to create and design learning environments that allow learners to participate in meaningful ways in education. In the next subsection, we focus on dialog as an analytic and normative concept (in terms of dialogic education) in our framing of a pedagogy for HRI and the notions of boundary object and boundary crossing.

\subsection{Theories and Practices of Education}

As outlined in the previous sections, HRI is a field that includes a variety of disciplines, methods, and epistemological assumptions. The implications of this argument are twofold: Firstly, the practices of HRI education are inevitably multifaceted and interdisciplinary, and secondly, the educational activities related to HRI should be framed in terms of dialogic education (Wegerif, 2013). Dialogic education emphasizes the multivoicedness of the educational practice, where no particular voice has more reason to exist than any other. Such an understanding of dialogue is inspired by the work of the Russian philosopher and semiotician Mikhail Bakhtin who framed dialogue in terms of the interaction between two or more participants and in the tension that is created by what is being said during that dialogue. Following a Bakhtinian vein, human communication is thus understood as dialogically oriented (i.e., as the encounter between words in a "living, tension-filled interaction"; 1981, p. 279). Nevertheless, dialogue, in such a line of thinking, is not limited to face-to-face, real time interaction among individuals but also encompasses dialogue by texts and other mediational means across time and space. Such an ontological and epistemological position is also strictly bound to an understanding of human cognition in terms of a socio-cultural continuum between agents and their cultural tools (Vygotsky, 1978; Wertsch, 1998).

The complexity and multifacetedness of HRI (as a dialogic activity) and the endeavor toward the creation of a shared curriculum and an own academic discipline (in terms of a monologic practice) may seem incompatible with one another. The move toward such a shared history lies in the creation of "complex cultural and technological environments" (Clark, 2003, p. 11) that support and facilitate communicative practices for a meaningful boundarycrossing among disciplines that seeks convergence (rather than conflict) in the multilayered and diverse patterns included in the HRI field. A focus on problem-based activities, rather than discipline oriented, could function as a boundary object, in line with Star's definition in terms of "a sort of arrangement that allow different groups to work together without consensus" (Star, 2010, p. 602, see also Star \& Griesemer, 1989). Such a perspective focuses on continuity (e.g., the creation of coherence and coordination across sites and disciplines). Following this line of thoughts, the oscillation between the ill-structured and well-structured aspects of boundary objects represent a cyclic process of the constitution of norms and rules (Star, 2010) (e.g., from novel/non-standard to established/standard methods and routines within a particular HRI educational practice). We suggest that such a cyclic process will also create educational standards and practice for the implementation of HRI as an academic discipline. This way of thinking is aligned with our suggestion to overcome and decrease the three identified "creative tensions" of the "epistemic living spaces" in HRI research (Weiss, 2012, 2016), as presented in Section 2.5. 
Montebelli et al., Reframing HRI Education

For example, at an earlier stage of implementation, a basic course in HRI for undergraduate students, with its curriculum and course material, may constitute a boundary object. The course functions in that case as a mean of transition across disciplines to create the sort of practical arrangements that are needed to allow dialogic practices to occur. Over time, a series of established routines will emerge in the course that sets the standards that eventually will become an integral part of the expectations that come with the course itself. This, in turn, implies that groups of students that will not align with the established standard and expectations will appear, and new boundary objects will be created to handle the discontinuity, in a cycle (Star, 2010). The implication of this argument is that boundary objects and dialogic education have the potential to promote the developments of an interdisciplinary "fluid" mindset, which is crucial for both HRI education and HRI research. The fact that HRI research encompasses the cooperation of people in academia, government, and industry is further evidence of the need for an interdisciplinary approach that focuses on real-life (global) problems and solutions, in the intersection of science and society. The Challenge Lab (http://www.challengelab.org), a project physically located at Chalmers University of Technology, Sweden, constitutes an example of how interdisciplinary work is a sine qua non condition to foster and educate practitioners to face complex problems that often incorporate global issues (e.g., global warming, sustainability, use of natural resources, etc.). The project also includes a master-level program where students meet and collaborate to learn how to cope with these issues now and how they could be achieved in the future. It is likely that the students who participate in the Challenge Lab's program contribute in creating epistemic living spaces and engage in the kinds of phases and transitions described by Weiss (2012, 2016-also see Section 2.4): an orientation phase, a positioning phase, and a stabilizing phase.

However, the transitions and tensions described above can be understood in terms of normative stances from an educational perspective, as they refer to activities that have the potential to foster learning toward specific directions and are in line with the kind of ontologies of educational activities that will be outlined in the next section of the paper. Thus and importantly, the issue of whether students who participate in the kind of program like the Challenge Lab or HRI master programs will eventually develop an interdisciplinary mindset that will allow them to develop the competences required to address interdisciplinary problems is an empirical question that lies outside the scope of this paper. What educational theories can provide at this stage is a set of tools and epistemologies that may contribute toward the design of activities that will foster a mobility of concepts and ideas which, in turn, is understood as promoting learning and development of individuals. Thus, the challenge in such an educational endeavor is to focus on boundaries and their learning potential (Akkerman \& Bakker, 2013, p. 133). Boundary crossing is a concept used in the study of how professionals need to use and enter a variety of domains of expertise without actually being the experts in that area and thus "face the challenge of negotiating and combining ingredients from different context to achieve hybrid situations" (Engeström, Engeström, \& Kärkkäinen, 1995, p. 25, as cited in Akkerman \& Bakker, 2013, p. 134). Examples of boundary crossing could be the activities related to the project planning, design, and construction of a building, the development, creation, and curation of a museum or the design and implementation of a (digital) tool. In a similar vein, the challenge in HRI is (beyond the design and implementation of the robot itself) the creation of a shared interactive space where humans and robots can meet. We argue that such an issue is also at the core of HRI education (i.e., the creation of the conditions for boundary crossing that also promote dialogue in an educational environment in terms of an epistemic living space).

\subsection{A Dialogic Ontology of Educational Activities}

Wegerif accounts for a dialogic ontology of educational activities in terms of the meaning that takes place "as an event only in the gap opened up by different perspectives in dialogue" $(2013, p .114)$. If this holds true for processes of knowledge creation and scientific enquiry, a variety of perspectives in pedagogical activities that pertains to HRI education seems to be a challenge that needs to be addressed and discussed. The image of HRI remains incongruous with the ways in which a variety of students identify themselves, especially those students who might choose to focus on the human and cognitive aspects of HRI (ref. Fig. 1). This implies the need of a pedagogy that is responsive to the diversity of voices within the group in a curriculum-based activity that both pertains to the cultural and academic belonging of the students, as well as their more personal interests that may (or may not) be related to external features, such as gender or ethnic affiliation. 
The dichotomy dialogic-monologic illustrates the distinction between activities that are open for alternative perspectives (dialogic) as opposed to traditions that aspire to the establishment of one truth that can be tested and falsified (monologic). Schools and other educational activities, and some technical subjects (see our distinction in Section 2.4), are often framed as monologic practices, since they aim at discovering the truth in Cartesian term (i.e., the most logically acceptable truth among a variety of voices, the one that is based on evident knowledge and discovered by the individual; Markovà, 2003). Thus, the multivoicedness of educational practices is not a prerogative of a dialogic pedagogy. In fact, monologic 'truths' may very well build upon dialogue and openness but start from radically different ontological positions about meaning making. Also here, as in all dichotomies, we may understand the meaning of one term by relating it to its opposite.

A focus on dialogic activities, as shown in Table 1, promotes the integration of diverse voices and processes of identification that will open up a shared interactional space where boundary crossing, and thus the creation of an epistemic space for dialogue, becomes possible. It should be noted that a dialogic space, open to a variety of standpoints and possibilities, is not equal to scientific relativism. The dichotomy monologic-dialogic does not imply that the former is more true and valid than the latter. Rather, what is central here (and a crucial part of the educational activities themselves) is the establishment of coherence across epistemologies and activities that will create an understanding and acceptance of difference not as an act of tolerance but rather as an endeavor to create an ontological foundation toward a common, interdisciplinary HRI framework (see also Rogers, 2015). Moreover, in line with the cyclic processes related to the creation of boundary objects outlined above, an HRI graduate program at master level, based on the dialogic ontologies presented in Table 1, could function as a boundary object to promote the overcoming of discontinuities that emerge from boundary crossing activities (i.e., during interdisciplinary work as well as in sociocultural differences among individuals). The potential that boundaries (and boundary crossing) hold as a resource for learning is a claim that is well established in educational theories. Here, the connection to dialogicality rests on the multivoicedness and diversity of the scientific domains, professional expertise, groups and organizations involved (or represented) in the educational activity.

Table 1: Monologic versus dialogic ontologies (adapted from Wegerif, 2015).

\begin{tabular}{|l|l|}
\hline $\begin{array}{l}\text { Monologic: } \\
\text { single voices }\end{array}$ & $\begin{array}{l}\text { Dialogic: } \\
\text { meaning through and across difference }\end{array}$ \\
\hline Reduces difference to one true perspective & Always more than one voice in play \\
\hline Meaning regarded as unsituated & Meaning depends on context (in a dialogue) \\
\hline $\begin{array}{l}\text { Progress linear: } \\
\text { Wrong views replaced by right views }\end{array}$ & $\begin{array}{l}\text { Augmentation: } \\
\text { Each new perspective adds insights }\end{array}$ \\
\hline Linear causation & \begin{tabular}{l} 
Complex causation \\
\hline Bounded (closed) totality
\end{tabular} \\
\hline
\end{tabular}

\subsection{Designing Pedagogy for Dialogic HRI Education}

Currently, HRI courses have a sparse diffusion. Berry (2015) reports the result of an internet query. She has identified and described five most relevant courses, four of which are targeted to graduate students and one to a mixed graduate/undergraduate audience. The existing courses tend to be designed ad hoc, serving specific and 
mostly technical needs rather than orchestrating the multifaceted aspects of the field. The situation is not much different in Europe and in the rest of the world, where few courses dedicated to HRI flank even more rare master's programs in service robotics. Despite the possibility of incomplete indexing of educational materials in the databases, this tentative picture of the field is confirmed by a search recently conducted by one of the authors in the education-oriented database ERIC. The research reported in the results from the database focus on robotics for education (rather than robotics or HRI education), on skills in coding and robot programming, or on general HRI themes with only minor connection to education.

Increasing financial support of introductory education in HRI by professional engineering societies, as well as by space and military agencies, is revealing of the strategies and interests involved. Content typically presented in advanced HRI workshops comprise social signal processing, robotics and autism, child-robot interaction, multi-modal communication, natural language interaction, smart environments, interaction design for robots, and robot ethics. However, these examples are often addressed from the more technical side of HRI. Berry (2015) has pragmatically described the design and implementation of a first course in HRI with a strong hands-on connotation, tailored to the needs of a largely non-technical audience of graduate and undergraduate students. She suggests that prerequisites can be limited to the understanding of general principles of object-oriented computer programming, AI, and HCI.

A workshop dedicated to HRI education was organized within a major conference in robotics (IROS 2009). Its outcomes were reported by Murphy et al. (2010). In the workshop, over 20 researchers focused on HRI education, sketching a perspective list of recommendations on course content, objectives, projects, and assignments. Their conclusion is a tentative list of minimal course objectives that highlight the interdisciplinary nature of HRI education. The successful students should be able to: define HRI, identify the key issues of HRI, know current applications of HRI, implement (social and non-social) skills in robots, implement safe interaction, transform robots into social platforms, and apply evaluation methodologies to HRI.

Since robots physically act in the real world, the most intuitive, effective, and typically rewarding way to learn HRI is through hands-on experience. However, several sources (e.g., Miller \& Nourbakhsh, 2016; Murphy, 2010) agree on the lack of cost-effective and pedagogically-appropriate robotic platforms for HRI. Off-the-shelf robots aimed toward sophisticated HRI are extremely expensive and still pose serious technical challenges. Potential pedagogical substitutes often lack options for the creation of rich interfaces.

The outcome of the IROS 2009 workshop highlights differences from the educational design that follows a dialogic pedagogy in a range of different ways. Firstly, it seems to illustrate how the different creative tensions outlined by Weiss $(2012,2016)$ can generate discontinuity, rather than boundary crossing, when the direction of the educational activity (like the workshop itself) focuses on the goal, rather than on the process. Secondly and related to the above, the list of requisites of the 'successful' HRI student is likely to generate a canon, where a range of skills gets framed in terms of absolutely necessary for the student from an a priori, normative position that clashes with the dialogic ontologies illustrated in Table 1. Finally, by framing the course outcome in terms of specific (technical) skills, the interdisciplinary, epistemic living space as learning environment is less likely to emerge precisely in its very effort to create and frame HRI as an independent, academic discipline.

We suggest that the student's mindset, which in general should be interdisciplinary and holistic, requires the following:

- A broad rather than a specialized interest in several of the fields on the current academic taxonomy;

- A multifaceted type of sensitivity, addressing issues ranging from technical to behavioral and psychological;

- The capacity to explore all such issues with deep understanding and critical thinking;

- The desire to engage in teamwork.

We should observe that these characteristics, differently from the ones identified by Miller and Nourbakhsh (2016), do not belong to the traditional toolbox of students in higher education. In fact, such characteristics might even be implicitly or explicitly discouraged by traditional academic offers. Currently, no academic curriculum aims for the integration of a broad articulation of loosely related sub-disciplines. 
In order to address the most technical aspects, an interest in technical subjects and a basic preparation in mathematics (calculus, linear algebra, and statistics) and classical physics are centrally significant. However, we should keep in mind that much effort in contemporary robotics is allocated to the development of natural and intuitive programming interfaces that tend to hide a large part of the most technical aspects and to mitigate the need for abstract mathematical thinking. This is not to discount the importance of technical capacity in HRI research but rather to emphasize that technical and computational components are necessary but not sufficient conditions in HRI education (Miller \& Nourbakhsh, 2016). In parallel, problem-solving and teamwork are fundamental abilities, because the development of robot systems requires coping with planning, diagnosis, and solving complex tasks through communication and cooperation skills. Within HRI education, students might still find opportunities to develop specialist-level competence, as long as specialization emerges within a robust organic vision. A dialogic education promoting boundary crossing encourages the creation of learning spaces where students with different backgrounds and competences, ranging across mathematics, computer science, engineering, interaction design, HCI, UXD, sociology, and anthropology, are combined, in order to provide several perspectives on the multifaceted field of HRI. This might increase the students' awareness that high quality interaction between humans and robots is not easily fulfilled from a single perspective. If students could realize the impact of their own competence on the overall HRI quality, they might develop a better appreciation of the potential of diversity, in terms of different competences and skills as well as the potentials that lie in sociocultural diversity.

We want to confront this brief snapshot of current HRI education with a general example of dialogic education, concretely experienced by two of the authors ${ }^{1}$ and applicable to HRI education. The space created in the flow of activity outlined in Fig. 2 is envisaged in terms of promoting and facilitating boundary crossing. The first preparatory phase of the educational module (or a whole course) includes engaging the students with the course content, as specified in the syllabus, and in the choice of further material. This phase may also include lab activities. In the early phase of artifact creation, students account for and illustrate what they perceive as central aspects of the course material, including a justification of the choice of the material on which they focus their creative experience. Artifacts produced by the students (consisting of texts and digital or analogue tools) are used as a point of departure in the seminar discussions that are at the core of the educational experience in terms of dialogic pedagogy. It is in this phase that students are trained in the kind of dialogic activities illustrated in Table 1 , where dialogic space must be shared for both conceptual discussion and hands-on experience. The space allocated for feedback is essential to the activity flow in Fig. 2. Feedback addresses the relation between the artifact itself and the students' beliefs matured during the preparation phase. The different potential implementations within the variety of relevant disciplines, shape and are shaped by the different phases in the activity flow but all aim toward a common theme/issue/solution in the specific course or course module. Both the curriculum-based goals, as well as the activity flow in terms of the creation of artifacts, are shaped in and through dialogic practices and function as boundary objects that allow for a common cognitive focus as well as for transitions thus recognizing a hybridization of learning across contexts (Akkerman \& Bakker, 2011). The final activity focuses on the assessment of the artifacts in relation to the course learning outcomes stated in the curriculum. During the assessment activity, the artifacts produced in the course so far cease to exist as boundary objects and are more specifically related to standards in the form of assessment criteria. Even though the activity of assessment seems to share a monologic view rather than dialogic (see Table 1), we suggest that also this practice is grounded in an understanding of the educational activity as open-ended, where the search for coherence, rather than universal "truths," is in focus. This implies a significant challenge for the teachers, who themselves represent a variety of disciplinary backgrounds and ontologies.

\footnotetext{
${ }^{1}$ G. M. D. and J. L.
} 


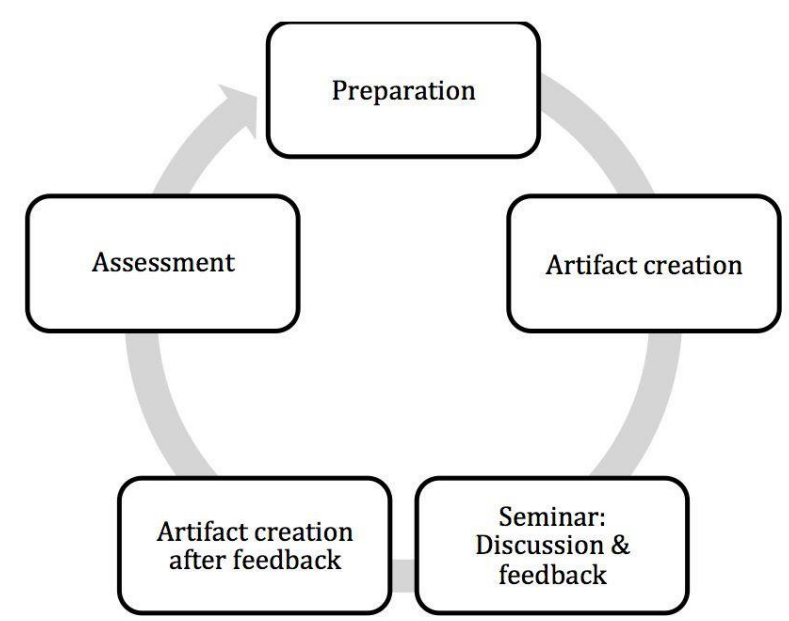

Figure 2: Activity flow in a dialogic educational space for HRI.

\subsection{The InDia Wheel: The Interdisciplinary Dialogic 'Wheel' for HRI Education}

Which approach to dialogic HRI education will best prepare students for the design of the space of interaction between humans and robots? We suggest that a plan for HRI education should include a backbone constituted of four main topics: engineering, natural cognition, artificial cognition, and interaction design. Crucially, and aligned with our dialogic approach, such a list should not be hierarchically interpreted. Each backbone topic: (i) has equal dignity; (ii) is complementary, integrally, and mutually related to the others; and (iii) cross-fertilizes with the others. In Fig. 3, we try to represent this network of relationships by suggesting a dynamic (spinning wheel) rather than a static (circle) interpretation of the picture. We call this the interdisciplinary dialogic wheel (in short, InDia wheel) for HRI education. This schematic representation should be imagined as having no 'up' or 'down,' no 'left' or 'right.' Each backbone topic in the wheel includes constituent sub-disciplines, also listed in Fig. 3. It is worth observing how the InDia wheel, in spite of its dynamic characterization, is related to Fig.1. The robot cognitioncentered vertex in Fig. 1 can be unfolded to form the natural and artificial cognition corners in Fig. 3. Similarly, unfolding the human-centered vertex generates the natural cognition and interaction design aspects in our description. 


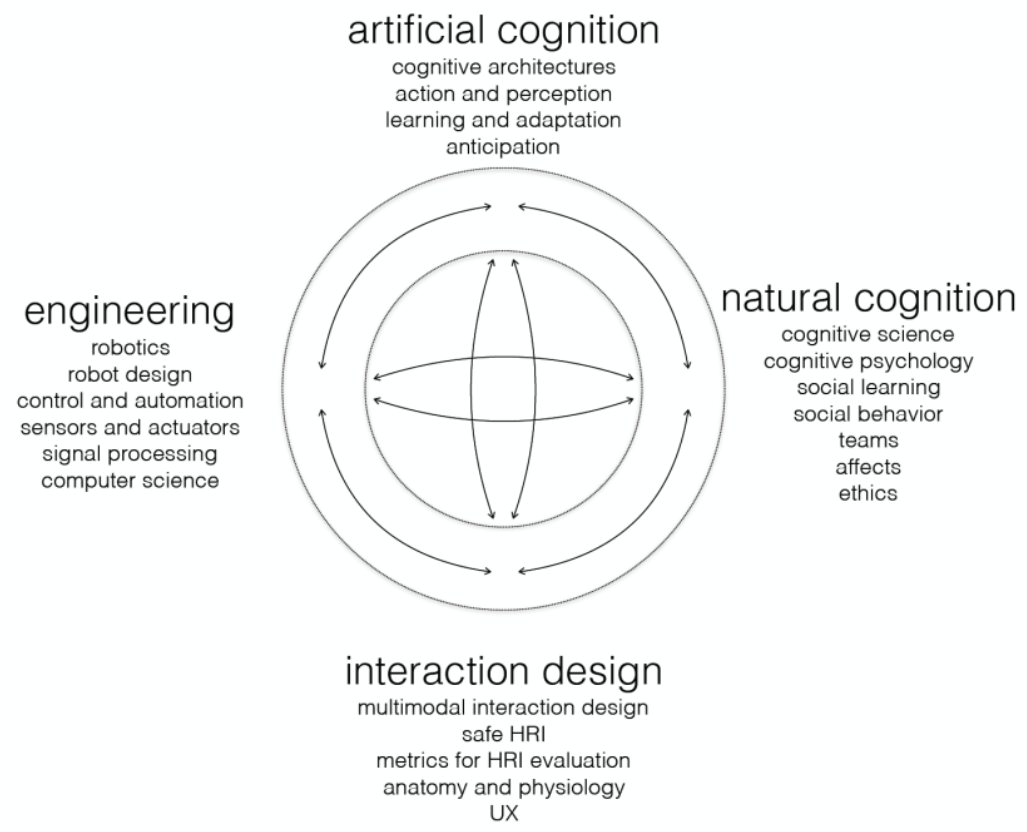

Figure 3: The InDia wheel for HRI education (see text) should be imagined as a nonhierarchical, dynamic, and mutual relationship among backbone topics and associated subjects.

Students should receive a solid exposure to all the backbone topics while being encouraged to relate to the organic structure of the field, although they will be naturally motivated by individual interest and strengths. We suggest that student training should be addressed with a holistic rather than specialist spirit in each sub-discipline.

Concretely, the dialogic learning experience can be articulated in terms of the flow of activities schematically presented in Fig. 4, which presents an example of the activities with the InDia wheel as a point of departure. Compared to Fig. 2, Fig. 4 constitutes a more specific, hands-on illustration of the impact of a dialogic ontology in the educational experience, as emerging from the InDia wheel metaphor. The preparation phase introduced in Fig. 2 is now framed in terms of the identification of the following: (i) a problem-based activity, which becomes the focus of the class and constitutes the boundary object (ref. Section 3.1) and (ii) an appropriate (activity-dependent) subset of sub-disciplines. Sequentially, each sub-discipline challenges the current object and can be imagined as specialistized 'lens' for the inspection and analysis of the context. The boundary object is here fully exposed, dissected, and analyzed in all its significant aspects, during what in Fig. 2 has been described as feedback and discussion phase. Alterations of the context (e.g., the synthesis of material and immaterial upgrades to the boundary object) that are specific to the sub-discipline, and their effects on the interaction quality between humans and boundary object can be observed and recorded under a broader interdisciplinary perspective. From a pedagogical point of view, in this phase the teacher's attention is not only focused on the final physical product of the activity but rather on promoting formative opportunities for the participants by creating and maintaining high quality and ongoing interaction within the class. At the conclusion of the discussion and feedback phase, a new sub-discipline (i.e., a new lens) is applied to the context. This cycle continues until the pedagogic potential of the activity can be considered as having reached a saturation point with the convergence to standard methods and routines in the activity $^{2}$. Throughout the process, up to this final point, the boundary object has been the practical arrangement through which the activity could take place even in a lack of general consensus (ref. Section 3.1).

\footnotetext{
${ }^{2}$ However, as a consequence of the dialogic approach, educational activities are open-ended (see Table 1).
} 


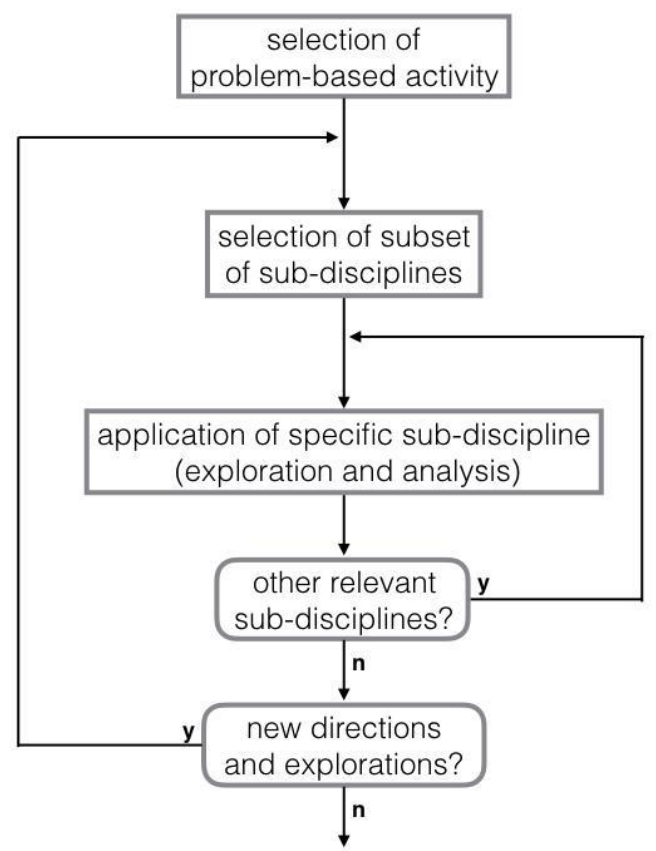

Figure 4: Example of a dialogic learning experience, as inspired by the InDia wheel for HRI education. The exploration of each activity should involve students over a timeline that can range from a few weeks to a whole semester.

At first sight, especially under the bias of traditional education, this approach might appear problematic. Within the framework that we propose, a number of empirical questions are generated and need to be operatively addressed and transformed into HRI-specific pedagogical practice. For example, would the students achieve deep knowledge about all the relevant aspects of HRI that are currently developed in specialist courses? Would strong competences in robotics, social behavior, and UXD find opportunities to emerge in parallel within the common academic constraints? In addressing these important concerns, there are two aspects of the framework here suggested that should be carefully considered. The first is the temporal frame. Each boundary object could be the working context for several weeks and up to a whole semester of activity. The second aspect is that contemporary pedagogy offers a new set of methods that can be usefully deployed at the undergraduate and graduate levels of higher education. The next section discusses new opportunities offered by these methods.

\section{Pedagogical Opportunities in HRI Education}

\subsection{HRI Education: Looking Ahead}

A first aspect worth mentioning is a recent trend in educational robotics programs in terms of robotics for education (Miller \& Nourbakhsh, 2016). This means that robotics as an educational field is used as a shortcoming for the achievement of higher cognitive (general) skills, such as problem solving, programming, design, and more generally, the STEM disciplines (science, technology, engineering, and mathematics). In other words, the link 
Montebelli et al., Reframing HRI Education

between education and robots lies in the learning potential that robots, as well as the design and programming of robots, seem to offer to their users (and designers). Miller \& Nourbakhsh make a strong case by claiming that "[e]ducation is itself a broad area of application for robotics" (2016, p. 2116) within, for example, ICT curricula. Furthermore, Miller and Nourbakhsh (2016) outline a set of three roles that robots may play in educational settings: (i) robot as programming project (i.e., in terms of black box) that can be programmed and whose actions are a manifestation of the coding activity behind the actions; (ii) robot as learning focus (i.e., the creation and use of robots as a means and goal in itself to stimulate a general interest in STEM disciplines as well as to enhance general skills, such as teamwork and problem solving); (iii) robot as learning collaborator, (i.e., playing a social role of aide and companion during learning activities). These points indicate that for some reason intrinsic to the particular relationship between humans and robots (and not yet completely understood), robots are likely to instantiate a privileged educational support. They appear to promote focus, motivation, and persistence by offering students a tangible multimodal feedback within a shared space of interaction.

In addition, general pedagogical opportunities have recently evolved in ways that seem appropriate for HRI education. For example, over the last few years, a number of Massive Open Online Courses (MOOCs) have freely distributed basic knowledge in the form of online videos of high-quality lectures and other digital material. Several prestigious institutions and distinguished teachers are actively contributing. A large part of this material is potentially relevant to interdisciplinary HRI education. In parallel, the concept of flipped classroom has found new energy in both lower and higher education (Bishop \& Verleger, 2013; Roehl, Reddy, \& Shannon, 2013; Tucker, 2012). According to this teaching method, prior to attending their class, students engage with different chunks of didactic material in an asynchronous and highly personalized way. Due to the heterogeneous population of HRI as educational field, this is a particularly important feature. For example, students with a stronger background in the human-centered view of HRI might take a slower pace in the assimilation of technical material. Vice versa, students with a technical background will invest more energy in the assimilation of human-centered material. The method can effectively integrate different media (e.g., video lectures, lecture notes, textbooks, and research articles). Each medium will differ from the others on the basis of the type of the information that it can most efficiently deliver. As a result of the flipped classroom, teachers' energy can be fully invested in the classroom, supporting the kind of dialogic activities illustrated in the previous sections of this article.

Plugging this scenario into the dialogic approach to HRI education that we suggest, while different media may asynchronously deliver information directly to the students, HRI educators become catalysts in the educational process. Teachers: (i) orchestrate the organic nature of the didactic material; (ii) indicate reasonable problem-based activities and goals that naturally progress toward more holistic and complex tasks; (iii) help their students in forming a personal view of the field, based on the individual's background and potential; (iv) and facilitate critical thinking and the development of students' communicative and affective maturity in their interactions with peers and supervisors. The latter skill is of crucial importance in the future of HRI designers and a milestone for integration into their intellectual community. In fact, future professionals will be able to access high-quality information about virtually any topic, more rapidly and in higher quantity than in any other epoch of human history. Their capacity to critically select appropriate material and to effectively position themselves into the professional community is strategically important. Class and group discussions, based on research articles (or even selected science-fiction literature and movies) have already been suggested as an ideal learning strategy, due to their appeal to students (Murphy et al., 2010) and might complement (if not substitute) more traditional lectures. The dialogic approach to HRI education here described can apply to undergraduate education and gradually progress toward more complex concepts and projects, naturally evolving to the highest educational level.

The practical application of the InDia wheel to HRI education (ref. Section 3.4) constitutes a significant challenge for the teachers involved in the program and there is a risk of overlooking the importance of the teacher's role, as well as the appropriate learning environment, within the picture we have sketched. Regarding the former, complying with the general dialogic and interdisciplinary framework outlined in Section 3.4, and further illustrated by the InDia wheel, challenges the teachers in terms of knowledge, self-confidence, experience, and sensitivity to classroom dynamics and 
Montebelli et al., Reframing HRI Education

flexibility in managing complex and dynamic scenarios. The creation of what we have framed in terms of 'epistemic living spaces,' using Weiss' $(2012,2016)$ terminology, includes the design of spaces for learning (including VLEs) that are open to diverse thinking both in terms of academic interdisciplinarity, and of the sociocultural background and identification processes for students and teachers. Here, the practices of inclusion of reusable learning objects (RLOs) or the content offered in MOOCs could be framed in terms of opening up the course and its space toward a dialogic pedagogy. However, such practices might be double-edged swords, as they reinforce the convergence toward a monologic 'golden standard' offered by an elite collection of the most established voices rather than in the dialogic experience where a multitude of voices should be included: "MOOCs prominence engenders fear of standardization and de-professionalization among some critics" (Tucker, 2012). The teacher's function and the availability of favorable learning environments, far from trivialized, are simply redefined by the new requirements.

\subsection{The Social Role of HRI Education and Youth Outreach}

Due to the expected, far-reaching diffusion of HRI, ranging from social robotics to hybrid biotech applications, HRI education addresses two crucial yet very different social functions. The first, more specifically targeted toward interested and motivated students, is to prepare a new generation of HRI designers. The second, more broadly distributed across society, is to prepare robot-savvy future generations. So far our work has mostly focused on the former aspect. However, future generations should form a generalized non-naive understanding of autonomous machines that increasingly populate our daily environment. We are not advocating the global dissemination of robot-related technicalities but rather the extension to all the members of the human society of the capacity to occupy an appropriate position in their interaction with robots.

We believe that the best strategy to address this second goal, at the same time preparing good candidates for the achievement of the first, is to turn our attention to children and adolescents. The intention, rather than rushing the process of their intellectual development and augmenting intellectual pressure and expectations on them, would be to expose students in primary and secondary education to simple robots, to offer a basic yet clear insight about what a robot actually is, thus promoting diversity and equality from an early age. Young students could directly experience different forms of interaction with robots or imagine new ones, well before they could start exploring all corollary technicalities. Youth outreach would endow the HRI community with the capacity to identify, contact, and motivate talented students at an early stage. In parallel, the creation of robot-savvy citizens would be a direct byproduct of the outreach, and this effect would partly extend to their families. To fully support the exploration of this approach, higher HRI education should establish contacts and collaboration with teachers in primary and secondary education. While building on and developing existing pedagogical experiences and programs, a focal point would be the detailed definition of the targets and scope of youth outreach activities and the mobilization of the necessary human, technical, and financial resources.

Several pioneering initiatives are already exploring these directions. A program running under the National Centre of Competence in Research - Robotics and funded by the Swiss National Science Foundation is developing a leading experience. On a local or international scale, several initiatives can be easily identified, aiming to trigger an interest in technology in younger students, with a special focus on women. For example, Girls in Tech is active in France, UK, Romania, Italy, and Portugal and is currently expanding across the rest of Europe. Aspirations in Computing is a program supported in the United States by the National Center for Women \& Information Technology. This entity financially supports young talented students (e.g., offering small salaries, free computers, etc.) and provides integrative educational stimuli (e.g., seminars and visits to major research institutions in the US).

\section{CONCLUSION}

HRI is a rapidly evolving, complex, and multifaceted discipline, whose main goal is the specification and design of a mutually shared interactive space between humans and autonomous machines. Efficient and effective HRI aims for functional and affective support of humans in their daily life. In other words, HRI design builds on technical and 
Montebelli et al., Reframing HRI Education

nontechnical mastery in order to meet pragmatic and socially significant goals. Ideally, HRI education should assist students in developing their individuality, engaging them in creative activities over the wide variety of HRI-relevant competences and free them from conformist thinking.

This article expresses the position of the authors on HRI education. However, we have theoretically framed our understanding in dialogic normative terms, based on currently limited literature in the field and on our direct experience as researchers in several fields of HRI (including robot programming for physical HRI, cognitive robotics, social supportive robotics, cognitive science, UXD, and pedagogy), and as teachers involved in different aspects of higher education at graduate and undergraduate level. In this article, we have focused on the interdisciplinary nature of HRI, advocating the pedagogic appropriateness of a dialogic approach to HRI education for the accomplishment of HRI's main objectives. The method that we suggest, visually summarized in the InDia wheel described in Section 3.4, has the potential to organically coordinate the often dissonant voices that characterize HRI as an interdisciplinary effort. Dissonances can emerge from the intrinsic multiplicity of disciplines that constitute HRI, as well as from the cultural and anthropological heterogeneity that typically accompanies curriculum-based activity.

Far from being a liberal extravagance, positive responsiveness to the diversity of voices coming from students and practitioners (including diversity in age distribution, gender, ethnic affiliation, and broad rather than specialized set of backgrounds, competencies, and interests) might represent an important added value for a relatively new and largely unexplored field such as HRI. Both theoretical (Page, 2007, 2011) and empirical research (Herring, 2009; Lee, Alston, \& Kahn, 2015; Richard, 2000) point to the importance of creating diversified groups in complex problem solving. For HRI, this also entails the opportunity to incorporate contributions from a variety of social groups that, for several reasons, are traditionally underrepresented in STEM courses.

For example, women constitute a particularly endangered population in STEM. Several statistical analyses of the tech industry suggest that women's capacity to impact design decisions in technology is currently marginal. While traditional claims about women's lack of natural ability for complex mathematical concepts have been deemed "inconclusive and incomplete," some authors focus on lack of persistence as a main factor for women's limited participation in STEM (Lee et al., 2015). The studies reviewed by Lee et al. highlight the relation between persistence and three motivational variables (achievement motivation, belonging, and experience of interest). Although unjustified, negative stereotypes (e.g., the belief that women have poor mathematical ability) negatively affect motivation and, consequently, persistence. Similar warped dynamics also apply to other groups (e.g., based on ethnicity). We believe that the dialogic approach that we have presented in this article, by focusing on a sequence of problem-based activity while relying on the motivational and persistence-inducing property of educational robots (See Section 4.1), might promote diverse participation. Our focus introduces new elements in the narration that traditionally describes HRI-related courses, deemphasizing the most technical and stereotypical aspects.

In parallel to their technical skills, and as a consequence of dialogic interdisciplinary work, we expect students to expand their understanding of the societal and ethical impact of HRI. For example, through large investments in robotics, innovation-oriented companies may receive a crucial strategic advantage over their competitors, as well as in negotiation with labor unions. How human societies will redistribute the profit derived from investments in robotics will be a challenging yet crucial factor over the years to come. Although the debate is still in its infancy, these kinds of social dynamics should be made fully intelligible to all involved future HRI stakeholders, users, and designers.

As a followup of the normative theoretical framework presented in this article, much empirical work is required, in order to confirm our claims and calibrate the approach that we have outlined in these pages to the specific needs of HRI education. For example, there is a need to implement and evaluate the InDia wheel model in practice, while further developing, in detail, activity integrations, course modules, and study programs for HRI education. This decisive endeavor is left for future work. Nevertheless, we hope that our effort will contribute to the creation of that mutually informative virtuous cycle between theoretical insight and empirical refinement that is still largely missing in HRI education, yet essential to its prospective development. 
Montebelli et al., Reframing HRI Education

\section{Acknowledgements}

The authors would like to thank the anonymous reviewers, whose comments helped us to focus and improve our manuscript. Alberto Montebelli thanks Silvestro Micera, Dario Floreano, and Luis Sentis for inspiring discussions that are at the origin of this work. He is also deeply grateful to his coauthors. In particular, G. M. D. and J. L. have critically contributed, transforming this manuscript into our 'boundary object,' on which the interdisciplinary and dialogic challenges addressed in the article have actually emerged and materialized. G. M. D. and A. M thank the multidisciplinary research group Communication, Culture and Diversity (CCD) for generous and kind hospitality during the writing retreat in 2016. The work of A. M. and J. L. was supported by the Knowledge Foundation, Stockholm, under SIDUS grant agreement no. 20140220 (AIR, "Action and intention recognition in human interaction with autonomous systems").

\section{References}

Akkerman, S., \& Bakker, A. (2011) Boundary crossing and boundary objects. Review of Educational Research, 81(8), 132-169.

Alenljung, B., Lindblom, J., Andreasson, R., \& Ziemke, T. (2017). User experience in social human-robot interaction. International Journal of Ambient Computing and Intelligence, 8(2), 13-23.

Bagga-Gupta, S., Messina Dahlberg, G., \& Winter, Y. (2016). Disabling and enabling technologies for learning in higher education for all: Issues and challenges for whom? Informatics, 3(4).

Bakhtin, M. (1981). The dialogic imagination: Four essays. C. Holmquist (Ed.). Slavic Series (Book 1). Austin: University of Texas Press.

Bauer, A., Wollherr, D., \& Buss, M. (2008). Human-robot collaboration: A survey. International Journal of Humanoid Robotics, 5(01), 47-66.

Berry, M. C. (2015). Teaching a first course in human-robot interaction. In Proceedings of the 122nd ASEE Annual Conference and Exposition. Seattle, WA.

Bishop, J. L., \& Verleger, M. A. (2013). The flipped classroom: A survey of the research. In Proceedings of the American Society for Engineering Education Annual Conference. Atlanta, GA.

Bødker, S. (2006). When second wave HCI meets third wave challenges. In Proceedings of the 4th Nordic Conference on Human-Computer Interaction: Changing Roles (pp. 1-8). ACM. Oslo, Norway.

Bødker, S. (2015). Third-wave HCI, 10 years later-Participation and sharing. Interactions, 22(5), $24-31$.

Charalambous, G., Fletcher, S., \& Webb, P. (2015). Identifying the key organisational human factors for introducing human-robot collaboration in industry: An exploratory study. The International Journal of Advanced Manufacturing Technology, 81(9-12), 2143-2155.

Clark, A. (2003). Natural-born cyborgs: Minds, technologies, and the future of human intelligence. Oxford: Oxford University Press.

Dautenhahn, K. (2007a). Socially intelligent robots: Dimensions of human-robot interaction. Philosophical Transactions of the Royal Society B, 362(1480), 679-704.

Dautenhahn, K. (2007b). Methodology and themes of human-robot interaction: a growing research field. International Journal of Advanced Robotic Systems, 4(1), 103-108.

Dautenhahn, K. (2013). Human-Robot Interaction. In M. Soegaard and R.F. Dam (Eds.). The encyclopedia of human-computer interaction (2nd ed.). Aarhus, Denmark: The Interaction Design Foundation. Retrieved on August 25, 2013 from http://www.interaction-design.org/encyclopedia/human-robot_interaction.html 
Dautenhahn, K., \& Sanders, J. (2011). Introduction. In K. Dautenhahn and J. Sanders (Eds.). New frontiers in human-robot interaction (pp. 1-5). Amsterdam, Netherlands: John Benjamins Publishing Company.

de Graaf, M. M. A., \& Allouch, S. B. (2013). Exploring influencing variables for the acceptance of social robots. Robotics and Autonomous Systems, 61(12), 1476-1486.

Dewey, J. (1938/1997). Experience and education. New York: Touchstone.

Donald, M. (2001). A mind so rare. The evolution of human consciousness. New York: Norton.

Engeström, Y., Engeström, R., \& Kärkkäinen, M. (1995). Polycontextuality and boundary crossing in expert cognition: Learning and problem solving in complex work activities. Learning and Instruction, 5, 319-336.

Falter, D. D., Burks, B. L., \& Babcock, S. M. (1995). Remote systems for waste retrieval from Oak Ridge National Laboratory gunite tanks. Transactions of the American Nuclear Society, 73(CONF-951006).

Fong, T., Nourbakhsh, I. \& Dautenhahn, K. (2003). A survey of socially interactive robots. Robotics and Autonomous Systems, 42(3-4), 143-166.

Goodrich, M. A., \& Schultz, A. C. (2007). Human-robot interaction: A survey. Foundations and Trends in HumanComputer Interaction, 1(3), 203-275.

Harrison, S., Tatar, D., \& Sengers, P. (2007). The three paradigms of HCI. In Proceedings of the Alt. Chi. Session at the SIGCHI Conference on Human Factors in Computing Systems (pp. 1-18). San Jose, CA.

Hartson, R., \& Pyla, P. S. (2012). The UX book: Process and guidelines for ensuring a quality user experience. Amsterdam: Morgan Kaufmann.

Hassenzahl, M., \& Tractinsky, N. (2006). User experience-A research agenda. Behaviour and Information Technology, 25(2), 91-97.

Hassenzahl, M. (2013). User experience and experience design. In M. Soegaard and R.F. Dam (Eds.). The encyclopedia of human-computer interaction (2nd ed.). Aarhus, Denmark: The Interaction Design Foundation. Retrieved on September 15, 2013 from http://www.interactiondesign.org/encyclopedia/user_experience_and_experience_design.html

Herring, C. (2009). Does diversity pay? Race, gender, and the business case for diversity. American Sociological Review, 74, 208-224. doi:10.1177/000312240907400203

Hochberg, L. R., Bacher, D., Jarosiewicz, B., Masse, N. Y., Simeral, J. D., Vogel, J., . . Donoghue, J. P. (2012). Reach and grasp by people with tetraplegia using a neurally controlled robotic arm. Nature, 485, pp. 372-375.

Hutchins, E. (1995). Cognition in the wild. Cambridge, MA: MIT Press.

Jasanoff, S. (2004). States of knowledge: The co-production of science and the social order. London: Routledge.

Lee, J. K., Alston, A. T., \& Kahn, K. B. (2015). Identity threat in the classroom: Review of women's motivational experiences in the sciences. Translational Issues in Psychological Science, 1(4), 321-330.

Lindblom, J., \& Alenljung, B. (2015). Socially embodied human-robot interaction: Addressing human emotions with theories of embodied cognition. In J. Vallverdú (Ed.). Synthesizing human emotion in intelligent systems and robotics (pp. 169-190). Hershey, PA: IGI Global, USA.

Lindblom, J., \& Andreasson R. (2016). Current challenges for UX evaluation of human-robot interaction. In C. Schlick and S. Trzcieliński (Eds.). Advances in ergonomics of manufacturing: Managing the enterprise of the future (pp. 267-277). Switzerland: Springer.

Lodwich, A. (2016) Differences between Industrial Models of Autonomy and Systemic Models of Autonomy. arXiv.org: 1605.07335

Markovà, I. (2003). Dialogicality and social representation: The dynamics of mind. Cambridge: Cambridge University Press. 
Montebelli et al., Reframing HRI Education

Miller, D. R., \& Nourbakhsh, I. (2016) Robotics for education. In B. Siciliano and O. Khatib (Eds.). Springer handbook of robotics (pp. 2115-2134). Switzerland: Springer International Publishing.

Montebelli, A., Steinmetz, F., \& Kyrki, V. (2015). On handing down our tools to robots: Single-phase kinesthetic teaching for dynamic in-contact tasks. In Proceedings of the IEEE International Conference on Robotics and Automation (ICRA), pp. 5628-5634. Seattle, WA.

Murphy, R. R., Nomura, T., Billard, A., \& Burke, J. L. (2010). Human-robot interaction: An exclusive course for computer scientists and engineers," IEEE Robotics and Automation Magazine, 17(2), pp. 85-89.

Norman, D. A. (2010). Natural interfaces are not natural. Interactions, 17(3), 6-10.

Page, S. E. (2007). The difference: How the power of diversity creates better groups, firms, schools, and societies. Princeton, NJ: Princeton University Press.

Page, S. E. (2011). Diversity and complexity. Princeton, NJ: Princeton University Press.

Powers, A. (2008) What robotics can learn from HCI. Interactions, 15(2), 67-69.

Raspopovic, S., Capogrosso, M., Petrini, F. M., Bonizzato, M., Rigosa, J.,. Di Pino, G, . . Micera, S. (2014). Restoring natural sensory feedback in real-time bidirectional hand prostheses. Science Translational Medicine, 6(222):222ra19. doi:10.1126/scitranslmed.3006820

Resnick, M. (1994). Learning about life. Artificial Life, 1, 229-241.

Richard, O. C. (2000). Racial diversity, business strategy, and firm performance: A resource-based view. Academy of Management Journal, 43, 164-177. doi:10.2307/1556374

Richert, A., Shehadeh, M., Plumanns, L., Gro, K., Schuster, K., \& Jeschke, S. (2016). Educating engineers for industry 4.0: Virtual worlds and human-robot-teams: Empirical studies towards a new educational age. In Proceedings of the IEEE Global Engineering Education Conference (EDUCON) (pp. 142-149). Abu Dhabi, UAE.

Roehl, A., Reddy, S. L., \& Shannon, G. J. (2013). The flipped classroom: An opportunity to engage millennial students through active learning. Journal of Family and Consumer Sciences, 105(2), 44-49.

Rogers, T. (2015). Critical realism and learning analytics research: Epistemological implications of an ontological foundation. In Proceedings of the Fifth Conference on Learning Analytics and Knowledge (LAK). March 16-20. Poughkeepsie, NY.

Rogers, Y. (2012). HCI theory: classical, modern, and contemporary. Synthesis Lectures on Human-Centered Informatics, 5(2), 1-129.

Rogoff, B. (1990). Apprenticeship in thinking: Cognitive development on social context. New York: Oxford University Press.

Scholtz, J. (2003). Theory and evaluation of human robot interaction. In Proceedings of the 36th Hawaii International Conference of System Sciences (HICSS). Big Island, HI.

Schuster, K., Groß, K., Vossen, R., Richert, A., \& Jeschke, S. (2015). Preparing for industry 4.0-collaborative virtual learning environments in engineering education. In Proceedings of the International Conference on E-learning in the Workplace (ICELW). June 15-17. New York, NY.

Shackel, B. (2009). Human computer interaction-Whence and whither? Interacting with Computers, 21, 353-366.

Star, S. L. (2010). This is not a boundary object: Reflections on the origin of a concept. Science, Technology, and Human Values, 35, 601-617.

Star, S. L., \& Griesemer, J. R. (1989). Institutional ecology, "translations" and boundary objects: Amateurs and professionals in Berkeley's Museum of Vertebrate Zoology, 1907-39. Social Studies of Science, 19, $387-420$. 
Montebelli et al., Reframing HRI Education

Steinmetz, F., Montebelli, A., \& Kyrki, V. (2015). Simultaneous kinesthetic teaching of positional and force requirements for sequential in-contact tasks. In Proceedings of the IEEE-RAS International Conference on Humanoid Robots (Humanoids), pp. 202-209. Seoul, Republic of Korea.

Thabet, M., Montebelli, A., \& Kyrki, V. (2016). Learning movement synchronization in multi-component robotic systems. In Proceedings of the IEEE International Conference on Robotics and Automation (ICRA), pp. 249 - 256. Stockholm, Sweden.

Thrun, S. (2004). Toward a framework for human-robot interaction. Human-Computer Interaction, 19(1), 9-24.

Thrun, S., Hähnel, D., Ferguson, D., Montemerlo, M., Triebel, R., Burgard, W., . . Whittakery, W. (2003). A system for volumetric robotic mapping of abandoned mines. In Proceedings of the IEEE International Conference on Robotics and Automation (ICRA). Piscataway, NJ: IEEE.

Tucker, B. (2012). The flipped classroom. Education Next, Vol. 12, No. 1, 82-83.

Tykall, M., Montebelli, A., \& Kyrki, V. (2016). Incrementally assisted kinesthetic teaching for programming by demonstration. In Proceedings of the 11th ACM/IEEE International Conference on Human-Robot Interaction (HRI), pp. 205-212. Christchurch, New Zealand.

Yanco, H. A., \& Drury, J. (2004). Classifying human-robot interaction: an updated taxonomy. In Proceedings of the IEEE International Conference on Systems, Man and Cybernetics (Vol. 3, pp. 2841-2846). Oct. 10-13. The Hague, Netherlands.

Young, J. E., Sung, J. Y., Voida, A., Sharlin, E., Igarashi, T., Cristensen, H. I., \& Grinter, R. E. (2011). Evaluating humanrobot interaction: Focusing on the holistic interaction experience. International Journal of Social Robotics, 3, 53-67.

Vernon, D. (2014). Artificial Cognitive Systems. Cambridge, MA: MIT Press.

Vygotsky, L. S. (1978). Mind in society: The development of higher psychological processes. Cambridge, MA: Harvard University Press.

Wegerif, R. (2013). Dialogic: Education for the Internet age. London: Routledge.

Wegerif, R. (2015). Dialogic. What is it? Can we measure it? In Proceedings of the Keynote Presentation at the 20th ELSIN Conference, June 1-3, Exeter, UK. http://www.rupertwegerif.name/uploads/4/3/2/7/43271253/ elsin_2015_wegerif_final.pdf

Weiss, A. (2012) HRI research: The interdisciplinary challenge or the dawning of a discipline? In Proceedings of the 7th Annual ACM/IEEE International Conference on Human-Robot Interaction (HRI) (pp. 271-272). New York: ACM.

Weiss, A. (2016) Creating service robots for and with people: A user-centered reflection on the interdisciplinary research field of human-robot interaction. Paper presented at the 15th joint Annual Conference of the Institute of Science, Technology and Society Studies at Alpen-Adria-Universität Klagenfurt|Vienna|Graz (STS), September, 23-24. Graz, Austria.

Wertsch, J. V. (1998). Mind as action. Oxford: Oxford University Press.

Ziemke, T. (2007) On the role of emotion in biological and robotic autonomy. BioSystems, 91, 401-408.

Ziemke, T., Thill, S., \& Vernon, D. (2015) Embodiment is a double-edged sword in human-robot interaction: Ascribed vs. intrinsic intentionality. In Proceedings of the Workshop on Cognition: A Bridge Between Robotics and Interaction, ACM/IEEE Human Robot Interaction Conference (HRI) (p. 9-10). Portland, OR.

Alberto Montebelli, University of Skövde, School of Informatics, Skövde, Sweden. Email: alberto.montebelli@his.se; Erik Billing, University of Skövde, School of Informatics, Skövde, Sweden. Email: erik.billing@his.se; Jessica Lindblom, University of Skövde, School of Informatics, Skövde, Sweden. Email: jessica.lindblom@his.se; Giulia Messina Dahlberg, University of Borås, Department of Educational Research and Development, Borås, Sweden. Email: giulia.messina_dahlberg@hb.se 